\title{
Theoretical Approaches to Investigate Self-Understanding: Literature Review
}

\author{
Ecaterina Postolati \\ Moldova State University, Chisinau \\ Faculty of Psychology and Educational Sciences ${ }^{1}$
}

Received 29 March 2018 • Revised 30 June 2018 • Accepted 13 July 2018

\begin{abstract}
In this informational-analytical paper results of the most relevant international research on selfunderstanding are analyzed and summarized. This work is aimed to summarize different approaches of investigating self-understanding from various perspectives of developmental psychology, psychology of knowledge, narrative psychology, psychoanalysis and humanistic psychology. An attempt is made to separate the phenomenon of self-understanding from selfknowledge, self-awareness, self-esteem, self-reflection, etc. The analysis of the features of selfunderstanding is carried out in the framework of two different tendencies: it is viewed as a cognitive phenomenon (emphasis on the process and result of the formation of knowledge about oneself) and as an existential phenomenon (appealing primarily to the value-semantic aspects of self-understanding).
\end{abstract}

Keywords: self-understanding, self-awareness, self-knowledge, cognitive phenomenon, existential phenomenon.

\section{Introduction}

The psychological development of the problem of self-understanding is one of the newest and promising areas of modern psychological science. Registration of this problem as an independent one occurred in the late $90 \mathrm{os}$ of the $20^{\text {th }}$ century. Throughout the century, many philosophers, psychologists and educators, while studying other psychological problems and in the context of various theoretical and methodological approaches, affected the problem of recognition, description and study of self-understanding, or understanding yourself in one way or another; sometimes even marking this concept with different meanings.

The term "self-understanding" is often used in psychotherapeutic and pedagogical practice. The need to understand ourselves, to understand our motives and feelings, thoughts and actions is characteristic to all people to a varying degree. This is evidenced by an increase in the number of popular psychological publications that call to understand and know yourself better. However, in scientific psychology, the problem of self-understanding did not arouse much interest among researchers. The interpretation of the phenomenon of self-understanding, describing the human "self", is given in the thesaurus in psychology (Walker, 1994) along with other terms that

${ }_{1} \mathrm{PhD}$ student.

(C) Authors. Terms and conditions of Creative Commons Attribution 4.0 International (CC BY 4.0) apply. Correspondence: Ecaterina Postolati, Sarmizegetusa str. 14/3, ap. 59, MD-2015, Chisinau, MOLDOVA. E-mail: epostolati@gmail.com. 
are of great importance for the personality psychology. Thus, self-understanding is part of the concepts that are significant for psychology.

In the course of studying, the problem of self-understanding was mentioned mainly in connection with the study of self-awareness of the individual. Self-understanding is regarded as a synonym for self-knowledge by A. N. Leontiev (1983) and Y. B. Gippenreiter (1988), selfawareness function - V. V. Stolin (1983), as a sign of a certain level of self-knowledge - I. I. Chesnokova (1977).

- There is no universally accepted definition of self-understanding in modern psychology.

- Self-understanding is tied with self-knowledge, self-awareness, self-reflection.

- There are two sides of self-understanding - cognitive and existential.

- As a cognitive phenomenon it emphasis the formation of knowledge about oneself.

- As an existential phenomenon it is appealing to the value-semantic aspects of being.

In the opinion of B. V. Kaygorodov, self-understanding brings into agreement the "Self-concept" with the reality. In the process of self-understanding the correlation, interaction and mutual influence of the "self", "self-concept" and "self-image" are brought into correlation. The main function of self-understanding is to comprehend the authenticity and meaning of the existence of one's "self" through the comprehension and understanding of the "self-image" and the "self-concept" (Kaygorodov, 2000).

It is quite peculiar that until recently the only dictionary where the definition of the phenomenon we are studying was met is the Dictionary of pastoral care and counseling, edited by R. Hunter (1990), where self-understanding is regarded as a person's ability to observe and explain his past, present and future motives and behavior. This definition of self-understanding in one form or another is used by all practical psychologists. It clearly identifies one of the main characteristics of self-understanding, namely a person's ability to self-observation, which consists in the fact that a person can expand their personal space and, through the definition of the most adequate "point of reference" to look at themselves in a new way. In its turn, the Oxford Dictionary of English (2003) later gave a more concise definition of self-understanding, as an "awareness of and ability to understand one's own actions and reactions".

In international psychological research, there are several main areas for studying the phenomenon of self-understanding. In developmental psychology self-understanding is seen as a cognitive representation of oneself. Self-understanding is aimed at differentiating a personality from society, emphasizing its individuality, originality, unsimilarity to others, state W. Damon and D. Hart (1982) and S. R. Cook-Greutor (1994). Within this area, self-understanding is considered as one of the key concepts for the development of the individual, and the main emphasis is made on studying the development of self-understanding primarily in childhood and adolescence.

\section{Approaches to investigate self-understanding}

The foundations of the study of self-understanding in the field of developmental psychology were laid by American psychologists W. Damon and D. Hart, who, based on W. James's (1891) ideas about two components of the human personality, namely, "self" as "I", the subjective knower (i.e., that aspect of the personality that organizes and interprets its experience and at every single moment is conscious of the reality, the world around and within itself) and the "self" as "me", the object that is known (that is, the totality of everything that a person understands as belonging to themselves, including, first of all, the physical, social and spiritual which characterize the uniqueness of their personality), explore the way in which children and adolescents come to understand the "self" as "me", as the object that is known (Damon \& Hart, 1982). 
Self-understanding, according to Damon and Hart, is a complex concept and is defined as "the cognitive representation of self, one's interest to their 'self' and individuality". In the process of self-understanding, as the researchers note, the "self" as "I", the subjective knower perceives the "self" as "me", the object that is known, consistently rising from the cognitive representation of their "physical self", that is - body, clothing, property - to the representation of the "social self", that is - social roles and relationships - and the "spiritual self", that is - the totality of their psychological properties and abilities. This process results in the formation of the concept of "self" in a child, which Damon and Hart are comparing, by its mechanisms, with the process of formation of any other concepts, forming during ontogenesis, etc. Thus, in fact, selfunderstanding, from the point of view of scientists, is nothing more than a "concept of the self". In the concept of Damon and Hart, self-understanding is a quite wide notion, which, in fact, is mixed with another related concept, that of self-awareness (Damon \& Hart, 1982).

The research of the American psychologist Cook-Greuter (1994) is dedicated to the study of development in the period of human's maturity. Personality development, according to her just remark, is a sequence of self-understanding stages, based on the stages of personality development. And each such stage is characterized by its own structure and ways of selfunderstanding. In her work author identifies and describes the three higher stages in the development of the adults' personality no younger than 26 years of age: autonomous, self-aware and universal. During the autonomous stage, a person strives to reach the limit of their possibilities and focuses their attention on self-realization, self-actualization, the creation of a complex, consistent and objective idea of themselves in order to be himself or herself to the maximum degree. In the next stage - the stage of self-awareness - the personality, as CookGreuter notes, explores their thought processes and attitudes and brings meaning into their own experience. The main focus is on "self" as a process and a meaning-generating center. And, finally, the goal of the last - universal - stage, according to Cook-Greuter, is simply "being". "Self" at this stage is described as a continuous flow, transformation, and the main way of self-understanding is meditation, observation of the continuous flow of changes, the subjective experience of direct knowledge of the deep reality outside of the symbols (Cook-Greuter, 1994). In our opinion, such an unusual point of view on self-understanding, when it is closely associated with states of consciousness and even interpreted in the spirit of oriental meditative practices, allowed to emphasize the role of this psychological phenomenon in the spiritual development of the personality, which is not limited to the level of its self-actualization.

In the study of self-understanding Cook-Greuter also draws attention to the fact that the more a person is differentiated, the more elements and diverse sources they can simultaneously process and integrate into an entire semantic structure. At the highest levels whole structures of knowledge or experience, interconnected and forming a new integrity, can act as elements. Inside this integrity, the researcher believes, dynamic interaction takes place between the "self-concept" and the surrounding world (Cook-Greuter, 1994). These arguments allow us to state that, first of all, self-understanding is based on differentiation of a person's ideas about themselves, which leads personality to a complex structure and integrity of the "self"; second, selfunderstanding possesses a level-like character, and at its highest levels there is a formation of a multiply connected structure or restructuring of ideas about oneself; and, thirdly, selfunderstanding contributes to the coordination of self-awareness products and reality.

The second direction of the study of the self-understanding phenomenon is associated with the psychology of knowledge. In this field of psychological science the term "selfunderstanding" refers to such concepts as "self-awareness", "self-knowledge", "self-relationship", "self-analysis", "self- reflection", but does not duplicate any of them. At the present time, there is no universally accepted definition of self-understanding, which most researchers agree with. Because of terminological vagueness, this problem sometimes cannot be separated from the problems of adjacent areas. 
Self-understanding as a cognitive representation of oneself is examined in the works of M. Dymkowsky (1993), C. Sedikides, and J. Skowronski (1995). Authors do not distinguish selfunderstanding and self-knowledge and describe this integral concept as a set or even a system of autoschemes, or well-organized structures of knowledge about oneself. Autoschemes have a dual nature, being both a process and a structure, a hypothesis or a model that is correlated with incoming information. Dymkowsky (1993) writes that self-knowledge or self-understanding can be interpreted as a cognitive prototype, multidimensional space, or as a cognitive category with internally hierarchical structure, as a stable categorical structure, or as a representation in sign, thematic, and mathematical form.

The analysis of publications on the problem of self-knowledge shows that implicitly the authors adhere to two positions concerning the relationship of these phenomena.

(1) In some works, in particular the ones that analyze sources of self-knowledge, these concepts are identified. So, self-knowledge and self-understanding are used as synonyms in Dymkowsky's book On self-knowledge and knowledge about oneself, where the author specially notes that in this work the terms "self-knowledge" and "self-understanding" are interchangeable. Dymkowsky says that self-knowledge begins with a review of one's own life, when external steps and internal conditions are analyzed and a person gets an opportunity to gain an understanding of how they are developing and to critically evaluate their spiritual and intellectual essence. This description of self-knowledge also corresponds to the above interpretation of self-understanding (Dymkowsky, 1993).

(2) In other studies, realized by B. Brown self-knowledge is defined as the entire amount of information about oneself, represented in the individual consciousness, or the cognitive representation of oneself, that part of the knowledge of the individual that is meaningfully referring to oneself as to a single whole or to some aspect of this whole. It should be noted that the concepts of "self-understanding" and "self-esteem", unlike the pair "selfunderstanding - self-knowledge", almost do not mix. Self-esteem emphasizes a positive or negative mode of perception of oneself, one's abilities, qualities, a place among other people, while self-understanding emphasizes the causes and meaning of one's own behavior and their attitude towards others (Brown, 1988). However, in R. Mills's work A new understanding of self: The role of affect, state of mind, self-understanding, and intrinsic motivation, self-understanding actually equals to self-esteem (Mills, 1991).

The circle of concepts that are adjacent to "self-understanding" also includes selfreflection. There is always an equal mark between the phenomena of reflection and selfunderstanding. So, for example, in the article of Sedikides and Skowronski, self-reflection is described as "active and coming from within thinking, which often arises from an attempt to attribute a certain meaning to events rather than to gather thoughtlessly all the facts relating to oneself" (Sedikides \& Skowronski, 1995).

Thus, self-understanding is examined and studied not only in the publications dedicated to this phenomenon, but also in the studies of self-awareness, self-knowledge, selfesteem, etc. In the context of the study of self-awareness problem, the phenomenon of selfunderstanding is also encountered in the work of I. I. Chesnokova, where self-knowledge is considered as one of the structural components of self-awareness of the individual, as a process of moving from one knowledge of oneself to another knowledge, its refinement, deepening, and amplification by other people.

Self-knowledge is a complex, multi-levelled process, individualized in time. Selfunderstanding, in its turn, is the highest level of the self-knowledge development. That level of self-awareness development on which a person achieves the most mature and true understanding of themselves, their social essence, awareness of their true worth, characterizes the highest stage of their formation as a personality (Chesnokova, 1977). 
3. The cognitive component of self-understanding and its connection to self-awareness

The interpretation of self-understanding in modern psychology is very ambiguous, and this fact generates a significant difference in the approaches and methods of this phenomenon research. In this regard, V. V. Znakov wrote that modern scientific research shows that selfunderstanding is both a holistic, integrative, and heterogeneous, multidimensional psychological phenomenon. As the researcher noted, when trying to define "self-understanding", psychologists usually pay most attention to different sides of self-understanding - either cognitive, or existential, connected to being (Znakov, 2005).

Self-understanding as a cognitive phenomenon is a subject of developmental psychology, where the concept of self-understanding belonging to Damon and Hart is the most advanced. Authors introduce the concept of the "locus of actual development", which suggests that children of any age have a certain understanding of all aspects of the "self" as me, the object that is known, and its significance for their development changes with age. Damon and Hart state that every aspect of self-knowledge is represented in the self-understanding of all people from childhood to adulthood. However, the understanding of each side of the "self", that is, the quality of the judgment about it, undergoes changes with the development of the personality. It is assumed that different levels of understanding are hierarchically subordinate: the lower apprehensions of self are constituent parts of higher levels. The study of the phenomenon of selfunderstanding from infancy to adolescence allowed the authors to identify the following repetitive ontogenetic patterns (Damon \& Hart, 1982):

- a shift from the physical to the psychological self-concept;

- the appearance of stable social characteristics of the individual;

- an increase in the volitional and reflexive components of self-understanding;

- the tendency of integration of the self's individual aspects into a complete system.

Damon and Hart are also the authors of a series of studies in which the correlation between self-understanding and social cognition is analyzed. The results of the research showed that a high level of self-understanding development is associated with a high level of awareness of the concepts of interpersonal interaction, such as justice, power and friendship. Thus, selfunderstanding is the key component of an individual's understanding of their social world (Damon \& Hart, 1982). Nevertheless, the development of self-understanding, according to their studies is not limited to the development of an understanding of social interactions: these two phenomena are related, but they significantly differ from one another. Similar conclusions have been made about the relationship of self-understanding and understanding of others.

A special place in the study of the self-understanding phenomenon is reserved for the problem of distinguishing the subject from other people who play an essential role in the construction of a meaningful identity. Identity can be defined as a subjective concept of oneself as an individual, thus being a form of representation. There are no images of self that an individual can identify as specific objects without defining themselves. This identification implies that an individual can perceive themselves as a particular object, different from all others. According to the ideas of D. Kodol, it is important that the distinctive features be recognized socially; identity, together with other forms of representation, is not self-constructed by individual, but arises in the course of interaction in the processes of perception, cognition and communication, including the introduction of the individual into the social environment (Kodol, 1981). Therefore, selfunderstanding involves understanding oneself, first of all, as an object that has distinctive features.

The concept of self-understanding of B. V. Kaigorodov belongs to the area studying self-understanding as a cognitive phenomenon, since in this concept self-understanding appears as a system of human representations about oneself, becoming more complicated with each age 
stage. Self-understanding, according to B. V. Kaigorodov, has a complex structure, which is determined by the integration of its two sides. On the one hand, the structure of selfunderstanding can be represented by three interrelated components: the need-motivational (system-forming), the cognitive and the emotional-volitional. However, in the studies of this author, the dominant component is cognitive. The basis of the cognitive component is the person's knowledge of themselves, their openness to new experiences, techniques and ways of selfunderstanding. But self-understanding is not limited to knowing oneself as such. Selfunderstanding is interpreted as "knowledge of knowledge", the formation of the sense of knowledge about oneself, which is possible through the experience and the processing of this knowledge. In the opinion of B. V. Kaigorodov, self-understanding unites the self-concept with reality. The main function of self-understanding is to perceive the authenticity and meaning of the existence of one's self through the realization and understanding of the self-image and the selfconcept. Consequently, self-concept is a means and a way of understanding oneself, concentrating the concepts of a person about oneself, allowing them to interpret their own actions and behavior (Kaigorodov, 2000).

Thus, in the studies of B. V. Kaigorodov, self-understanding is a system of human representations about their individual psychological features, their attitude towards other people, the reflective attitude of others towards themselves, their motives and their place in the world. Self-understanding creates the "inner thesaurus of the personality as a system of concepts about oneself," which determines the content of the self-concept and through which meaning evolves into the behavior of a growing person.

Cognitive-oriented psychologists H. Markus and S. Kitayama introduce the concept of "self-interpretation", which is similar to the concept of "self-understanding". Self-interpretation is characterized as a constellation of thoughts, feelings and actions manifested in the relationship with others, and can be of two types, depending on the mode of self-determination: "independent self-interpretation" and "interdependent self-interpretation". In their works, authors give a detailed description of the motives, ways of self-determination, relationships with others and the most typical feelings common for people with these types of self-interpretations. Independent selfinterpretation is defined as being separated from others, a holistic and stable self, divided from the social context. The main characteristics of independent self-interpretation are: internal efforts, thoughts and feelings; a sense of uniqueness and self-expression; an internal locus of control; realization of a person's own goals and immediacy in communication. Dependent selfinterpretation is defined as a "flexible and changing" self, being influenced by the external properties of the environment, such as status, roles, relationships, belonging and adaptability, acquiring one's own position and engaging in relevant activities, interacting with others, and understanding others. In the self-concept of the owners of "interdependent self-interpretation" social identity prevails because they tend to describe themselves in terms of social roles, and the basis of their self-relationship is the correspondence to the expectations of others. Internal attributes are relatively less important for people who often think of themselves in relation to specific social relations or context (Markus \& Kitayama, 1991). Thus, self-interpretation is a certain attitude, manifested in a relationship with others, in which cognitive, affective and behavioral components are singled out. In accordance with the type of mental set in the self-concept of the individual, elements of personal or social identity prevail.

Summing up the analysis of self-understanding as a cognitive phenomenon, we should note the inseparable connection of self-understanding with self-awareness and reflection. It is also being debated upon whether self-reflection shows negative personal qualities - the inclination for heart-searching, the state of being fixated on one's own problems based on self-distrust. Many psychologists respond to this question negatively: the awareness of one's own inner world, attention to one's own thoughts and feelings contributes to an adequate adaptation to social reality in normal people (Scandell, 2001). In particular, M. B Connolly et al. (1999) writes that clients 
characterized as reflexive and eager for self-improvement, in the process of communication with a psychotherapist, reveal a deeper level of self-understanding of interpersonal relationships patterns.

4. The existential side of self-understanding as the semantic center of personality and the premise of self-actualization

As V. V. Znakov notes, from the standpoint of the existential approach, understanding is interpreted as a way of being a person in the world. Self-understanding in this case turns out to be such a phenomenon, whose sources should be sought by reflection of the value-semantic formations of the personality and the contexts of the subject's activity (Znakov, 2005). The existential aspect of self-understanding is regarded, first of all, in the context of narrative psychology, which draws an analogy between understanding the text and the person's understanding of themselves, their own behavior and the events of their life. In this approach, the concept of "self-understanding" is synonymous to the self-identification of the individual.

In his model of identity as a personal story, D. P. McAdams has started out from the notion of Erickson's ego identity and argues that identity itself can take the form of a story that contains a description of the situation, scenes, characters and the main idea. Identity must bring together different aspects of the self, so they can be meaningfully linked to each other in a certain temporal sequence. Identity, therefore, is a way of organizing personal experience. The researcher believes that life stories characterize individual peculiarities of people just as well as personality traits, motivation, etc. (McAdams, 1996).This principle was further developed by T. Sarbin, who asserted that human life, like a narrative story, has a plot, time sequence and important episodes. Therefore, the meaning of human activity and experience is expressed with the greatest completeness in the narrative (Sarbin, 1986).

In narrative therapy, the attention of researchers is drawn to the understanding of the psychotherapeutic situation as a narrative. Thus, in the article of Dean Ruth Grossman, various methods used in groups for changing the meaning, organizing the past, explaining the present and creating alternatives for the future are examined. Narratives are seen as forms of self-creation, they can be used to support or instruct, improve self-understanding and interpersonal relationships (Dean, 1998). Self-understanding in narrative psychology is seen as the creation of a "text" about self, as continuous self-interpretation. The basic position of the narrative approach to the study of this phenomenon is the consideration of the self as a product of co-building in the community. Self-understanding brings together various aspects of the self and is a way of organizing personal experience.

The next direction in the study of self-understanding as an existential phenomenon is psychoanalysis, where self-understanding is seen as the most important factor that allows the subject to change in the process of interaction with a psychoanalyst. Human understanding of their suppressed feelings, desires, leading to personal integration, is opposed to the defense mechanisms, primarily rationalization and intellectualization. The problem of the importance of self-understanding for the therapeutic process was posed by S. Freud. In his early works, he believed that the task of therapy is to turn the unconscious into the conscious, in order to learn the truth about one's own behavior and motivation. Most psychological symptoms are rooted in lack of understanding of oneself, ignorance of the true motives and emotions. Generally, this is the result of a struggle between desires emanating from the Id and the demands of the Superego (Freud, 1966). To date, the most recognized definition of the "self-understanding" concept in psychoanalysis is given by Appelbaum. According to this definition, self-understanding is the ability of the subject to discern the interconnections between thoughts, feelings and actions, in order to understand the causes and possible significance of the facts of their experience and behavior (Appelbaum, 1973). Developed self-understanding means the ability to experience 
psychological conflict and stress exclusively intrapsychically, without using such regressive forms of coping as somatization. Thus, self-understanding is the opposite of another psychological phenomenon - alexithymia, the inability of the subject to detect, identify and distinguish feelings, in psychiatry it is viewed as a source of great psychological difficulties. People suffering from alexithymia, in their turn, often have a tendency towards somatisation of the stress. A decreased level of self-understanding in the literature was often associated with tendency towards somatization of the stress, the use of psychoactive substances and the manifestation of antisocial behavior (Scandell, 2001).

Researchers identified 5 factors of self-understanding (Raingruber, 2000):

1. Desire to try to understand oneself and others;

2. Openness to new ideas and the ability to change;

3. Accessibility to the area of feelings;

4. Belief in usefulness of discussing psychological problems;

5. Interest in understanding the motivation and meaning of one's own behavior and behavior of others.

Thus, self-understanding in psychoanalysis, is the person's ability to understand the connections between thoughts, feelings and behavior, understanding the causes of behavior and the influence of past experience.

Unlike the psychoanalytic approach, humanistic psychology emphasizes not rational, but emotional, empathic character of self-understanding, which is closely connected with positive self-esteem and self-acceptance of the individual and gives the opportunity to live life more fully - to be yourself to the fullest extent. In the framework of humanistic psychology it is noted that the phenomenon of understanding another person is prior to self-understanding and the understanding of the situation of communication. Self-understanding is, in fact, understanding oneself as the other, suggesting the formation of a different vision of oneself, an attempt to look at oneself from another value-semantic position. On the one hand, understanding the other, the subject enriches themselves. Perceiving the life experience of another person, they also change, become different. On the other hand, the understanding of the partner by the subject also gives to the partner an opportunity to change and understand themselves in a different way (Rogers, 1961). Therefore, the understanding of the other and the understanding of oneself are considered in this scientific tradition as processes, similar in mechanisms and internal characteristics.

Since, according to V. V. Znakov, the result of self-understanding is information with a new meaning about oneself, self-understanding can be defined as the dynamics of semantic entities of personality in the areas, outlined above (Znakov, 2000). We propose to consider selfunderstanding as an intrapersonal dynamics of semantic entities in the process of self-knowledge.

The process of understanding the semantic connections is the reflexive work of consciousness, directed not so much to oneself, but to the world, and which consists in solving a special problem, called by A. N. Leontiev the "task of meaning". It is characterized by Leontiev as the task of comprehension of those motives that communicate meaning to various objects, phenomena and actions. The author explains that "the task of meaning is the task of determining the place of an object or phenomenon in the life of a subject" (Leontiev, 1983). It can be placed in relation to one's own action (what for I am doing it, did it or going to do it; what motives lay behind it, what needs or values are exercised through this action and what consequences it will lead to), and also in relation to objects, phenomena or the events of reality (what place do they occupy in my life, in my world, for which aspects of my life they are important, how can they affect it, what can the consequences be). As self-understanding implies awareness of the meanings and semantic 
connections already existing for the subject, we can assume that in this case we are dealing with the second type of dynamics of the semantic processes.

Self-understanding, thus, is an awareness of the semantic structures of the subject (values, goals, life position), the semantic connections of the subject (motives of behavior in a particular situation and the needs and values that stand behind them). Being the semantic center of the personality, self-understanding is considered as a precondition of personal growth and selfactualization. Self-understanding is closely connected with self-acceptance, positive self-esteem and gives the person the opportunity to live his life more fully, "to be themselves to the maximum extent” (Romanova, 1999).

\section{Conclusions}

Self-understanding simultaneously as a cognitive and existential phenomenon is one of the key issues in the psychology of human existence. In a number of works, V. V. Znakov considers self-understanding as a complex psychological phenomenon, highlighting cognitive and existential components in it (Znakov, 2000).

From the cognitive point of view, successful self-understanding is defined by the researcher as a meaningful result of observing and explaining a person's thoughts and feelings, motives of behavior. Znakov (2005) distinguishes three main areas of psychological analysis of self-understanding:

- Ability to discover the meaning of actions, to understand their individual psychological characteristics: knowledge, skills, motives, achievements, etc.;

- Ability to understand the specific nature and causes of how one understands other people, i.e. in a specific way and not in a different manner;

- Socially reflective components of self-understanding - how the others treat you and how they evaluate you.

Based on the analyzed scientific material, it is possible to draw the following conclusions about the signs of self-understanding as a cognitive phenomenon:

- Self-understanding is a system of human representations about their individual psychological features, their type of attitude towards other people, the type of reflective attitude of others towards themselves, their motives, their place in the world; introspective views of a person about their own individual intellectual resources.

- The structure of self-understanding includes a complex matrix of selfidentifications, and its configuration depends on the type of self-interpretation.

- The main task of self-understanding is to create a comprehensive, consistent and objective view of oneself.

- Self-understanding is not a static-ascertaining phenomenon, it has a constant internal movement.

- Self-understanding considerably influences the entire structure of the psyche, the world perception as a whole, and determines the basic line of human behavior.

- Self-understanding is achieved by thinking, by careful rational analysis supplemented by intuition and emotions.

The existential aspects of self-understanding are directed towards the search for the meaning of one's existence, actions, and a mental outlet not only beyond the limits of a particular communicative situation, but beyond the limits of one's own life, including it in some other coordinate system in which life is endowed with meaning. Znakov believes that self-understanding as a mental process is a gradual process of revealing, the person's discovery of the truth about oneself, i.e. correlation with the internal criteria of the development of the individual, the notions of social and ethical obligations (Znakov, 2000). 
Self-understanding as an existential phenomenon has the following characteristics:

- the desire of the subject to try to understand themselves and others;

- openness to new ideas and the ability to change;

- sensitivity to one's own desires and needs;

- interest in understanding the motivation and meaning of one's own behavior and the behavior of others;

- freedom from the psychological defense that separates the individual from their own essence;

- internal locus-control in the sphere of interpersonal relations;

- access to the feelings sphere;

- awareness of the subject's semantic structures (values, goals, life position), their semantic connections (motives of behavior in a particular situation and the needs and values that stand behind them);

- a reflexive understanding of the basic existential motivation (perception of values, meaning, attitude towards death, fears, etc.).

To conclude, at the moment, the analysis of the features of self-understanding is carried out in the framework of two different tendencies: it is viewed as a cognitive phenomenon (emphasis on the process and result of the formation of knowledge about oneself) and as an existential phenomenon (appealing primarily to the value-semantic aspects of selfunderstanding). The attempt to combine these approaches is made in the context of the psychology of human existence and the semantic theory of personality.

\section{Acknowledgements}

This research did not receive any specific grant from funding agencies in the public commercial, or not-for-profit sectors.

The author declares no competing interests.

\section{References}

Appelbaum, S. A. (1973). Psychological-mindedness: word, concept and essence. The International Journal of Psycho-Analysis, 54(1), 35-46.

Braun, B. (1988). Development of self-knowledge and the process of individuation. Polish psychological bulletin, 19(3), 257-262.

Chesnokova, I. I. (1977). Problema samosoznaniya $v$ psychologii [The problem of self-awareness in psychology]. Moskow: Nauka.

Codol, J. P. (1981). A cognitive approach to the feeling of identity. Social Science Information, 2O, 111-136.

Cook-Greuter, S.R. (1994). Rare forms of self-understanding in mature adults. In: Transcendence and Mature Thought in Adulthood. The Further Reaches of Adult Development (pp. 119-143). London: Rowman and Littlefield Publishers, Inc..

Connolly, M. B., Crits-Christoph, P., \& Shelton R. C. (1999). The Reliability and Validity of a Measure of Self-Understanding of Interpersonal Patterns. Journal of Counseling Psychology, 46(4), 472482.

Damon, W., \& Hart, D. (1982). The Development of Self-Understanding from Infancy through Adolescence. Child Development, 53(4), 841-864.

Dean, R. G. (1998). A narrative approach to groups. Clinical Social Work Journal, 26(1), 23-37. 
Dymkowsky, M. (1993). O samowiedzy i poznawaniu siebie [On self-knowledge and knowledge about oneself]. Wrocl.: Wyd. uniwersytetu wroclawskiego.

Freud, S. (1991). Vvedenie v psychoanaliz. Lectsii [Introduction in psychoanalysis. Lectures]. Moscow: Nauka.

Gippenreiter, Y. B. (1988). Metod introspektsii i problema samonabliudenia [The introspection method and the problem of self-observation]. Moscow: Moscow State University Ed.

Hunter, R. J. (1990). Dictionary of Pastoral Care and Counseling. Nashville: Abingdon Press.

James, W. (1891). The Principles of Psychology, Vol. 1. Cambridge, MA: Harvard University Press.

Kaygorodov, B. V. (2000). Samoponimanie: mifili relinosti [Self-understanding: myth of reality]. Moskow: Moskow Psycho-sociologicheskyi Institut.

Leontiev, A. N. (1983). Psychologia iskusstva i hudojestvennaya literatura [Psychology of art and the artistic literature]. Izbrannye psyhologicheskie proizvedeniya [Selected psychological works]: Moskow.

Markus, H. R., \& Kitayama, S. (1991). Culture and the self: Implications for cognition, emotion, and motivation. Psychological Review, 98, 224-253.

McAdams, D. P. (1996).The stories we live by: Personal myths and the making of the self(Chapter 4). New York - London: The Guilford press.

Mills, R. G. (1991). A new understanding of self: The role of affect, state of mind, self- understanding, and intrinsic motivation. $J$. of experimental education, $60(1), 67-81$.

Oxford Dictionary of English (2003). Ed. C. Soanes, A. Stevenson. Oxford University Press.

Raingruber, B. (2000). Being with feelings as a recognition practice: Developing clients' self-understanding. Perspectives in Psychiatric Care, 36(2), 41-50.

Rogers, C. (1961). On becoming a person: A therapist's view of psychotherapy. (Chapter 6). London: Constable.

Romanova, I. A. (1999). Samoponimanie lichnosti [Person's self-understanding]. Individualinyi $i$ gruppovoi subiekty $v$ izmenyaiuschemsya obshestve [Individual and group subjects in a changing society]. Moscow: Institut psychologii RAN. 131-132.

Sarbin, T. R. (1986). Narrative psychology: The storied nature of human conduct (Chapter 2). Princeton, NJ: Princeton University Press.

Scandell, D. J. (2001). Is self-reflectiveness an unhealthy aspect of private self-consciousness? The Journal of Psychology, 135(4), 451-461.

Sedikides, C., \& Skowronski, J. J. (1995). On the sources of self-knowledge: the perceived primacy of selfreflection. Journal of Social and Clinical Psychology, 14(3), 244-270.

Stolin, V. V. (1983). Samosoznanie lichnosti [Self-awareness of personality]. Moscow: Moskovskii Gosudarstvennyi Universitet.

Walker, A. (1994). Thesaurus of psychological index terms. Wash.: Amer. Psychol. Assoc.

Znakov, V. V. (2000a). Ponimanie kak problema chelovecheskogo bytyia [Understanding as a problem of the human being]. Psychologicheskyi jurnal [Psychological journal], 26(2), 7-15.

Znakov, V. V. (2005b). Samoponimanie subiekta kak kognitivnaya i ekzistentsyalinaya problema [Subject's self-understanding as a cognitive and existential problem]. Psychologicheskyi jurnal [Psychological journal], 26(1), 18-28. 
E. Postolati - Theoretical Approaches to Investigate Self-Understading: Literature Review

C O A $\mathbf{s}$ 